\title{
Antioxidant and anti-matrix metalloproteinases activities of dried longan (Euphoria longana) seed extract
}

\author{
Atita Panyathep $^{\mathrm{a}}$, Teera Chewonarin ${ }^{\mathrm{a}}$, Khanittha Taneyhill ${ }^{\mathrm{b}}$, Usanee Vinitketkumnuen ${ }^{\mathrm{a}, *}$ \\ a Department of Biochemistry, Faculty of Medicine, Chiang Mai University, Chiang Mai 50200 Thailand \\ b Division of Clinical Chemistry, Department of Medical Technology, \\ Faculty of Associated Medical Sciences, Chiang Mai University, Chiang Mai 50200 Thailand
}

*Corresponding author, e-mail: usaneecmu@yahoo.com

Received 22 Sep 2012

Accepted 20 Dec 2012

\begin{abstract}
Longan, a major fruit crop in Thailand, is a rich source of antioxidant polyphenic compounds, mostly gallic acid and ellagic acid. Dried longan seeds contain large amounts of antioxidant polyphenols. In this study, three fractions of dried longan seed extract were collected by Sephadex LH-20 column chromatography to determine the major compounds in each, and the amounts of gallic acid and ellagic acid were quantified. The first fraction was determined to be the major source of gallic acid, while ellagic acid was mainly found in fraction 3. Antioxidant activities were measured using total phenolic content, total flavonoid content, 2,2-diphenyl-1-picrylhydrazyl (DPPH) free radical scavenging activity, and metal chelating activity. Fraction 1 had the highest antioxidant activity. In addition, the effect of each fraction on matrix metalloproteinases (MMPs) activity was analysed using a fluorometric assay. Interestingly, fraction 3 had the greatest MMPs inhibitory effect. Notably, dried longan seeds have been established not only as major sources of antioxidants, but also as potent MMPs inhibitors. Since these properties are associated with anti-cancer effects, dried longan seeds could be a novel natural source for compounds used in chemoprevention and chemotherapy.
\end{abstract}

KEYWORDS: gallic acid, ellagic acid, HPLC, DPPH scavenging activity, metal chelation activity, MMP inhibitor

\section{INTRODUCTION}

Longan, Euphoria longana Lam. (syn. Dimocarpus longan Lour.) is a subtropical fruit widely grown in China and SE Asia, including Thailand, Vietnam, and the Philippines. In Thailand, longan, also known as 'lamyai', is a major fruit export. The fruit appearance includes a brown or light-brown peel with white translucent flesh, while the seeds are round and black with circular white spots at the base. Generally, the flesh is most popular for consumption fresh and in processed products such as canned longan in syrup or dried longan ${ }^{1}$. In Chinese medicine, the flesh of the fruit is used as a stomachic, febrifuge, vermifuge, and as an antidote for poison. The dried longan is also used as a tonic and for the treatment of insomnia and neurasthenic neurosis. While the seeds account for $17 \%$ of the fresh weight of whole fruits, these are usually discarded as a waste or burned as fuel. A previous study demonstrated that the aqueous extract of longan contained high levels of polyphenolic compounds such as corilagin, gallic acid, and ellagic acid $^{2}$. The content of these polyphenols was mostly found in dried seed extract, while pulp contained the lowest amounts ${ }^{1}$. Several studies have indicated that gallic acid and ellagic acid have important health benefits. Gallic acid possesses anti-cancer properties via anti-proliferation and apoptosis induction of certain types of cancer cells such as leukaemia, prostate, colon and lung cancer cells ${ }^{3-6}$. Ellagic acid has antioxidant, anticarcinogenic, antifibrosis, antiplasmodial and chemopreventive activity ${ }^{7-12}$. These data indicate that longan seed extract may be a new source of supplementary antioxidants and natural chemopreventive agents. Since the limitation of research on other biological activities such as anti-invasion and anti-metastasis, this present study is first manifestation of the dried longan seed extract action on the major modulator on metastasis processing, especially matrix metalloproteinases (MMPs).

MMPs are a family of secreted and transmembrane $\mathrm{Zn}^{2+}$ endopeptidases and are produced by host connective tissue or tumour cells. This family currently includes over 25 members that can be classified according to the organization of MMP domains as well as their specific substrate. The MMPs are multidomain enzymes; generally consisting of : (1) a signal peptide which is essential for secretion; 
(2) a propeptide domain that contains a conserve cysteine switch motif of PRCXXPD for maintaining the latency form of MMPs; (3) a catalytic domain that contains one catalytic zinc, one structural zinc, and, generally, three calcium ions and the zinc binding motif HEXGHXXGXXH; and (4) a hemopexin carboxy C-terminal domain ${ }^{13}$. Six groups can be distinguished, including collagenases (MMP-1, -8, and -13), gelatinases (MMP-2 and -9), stromelysins (MMP-3 and -10), matrilysins (MMP-7 and -26), the membrane-type MMPs (MMP-14 to -17 and -24), and other MMPs ${ }^{14}$. MMPs contribute to tumour growth, invasion, and metastasis by degrading the surrounding basement membrane and extracellular matrix barriers, resulting in migration of tumour cells. Based on our understanding of the characteristics of MMPs and the accumulation of evidence indicating a role for MMPs in cancer extension, considerable effort has been dedicated to developing effective MMP inhibitors (MMPIs) for the treatment of cancer.

The search for effective MMPIs has passed through several stages over the past 20 years ${ }^{15}$. The goal is to develop safe and effective MMPIs for cancer patients. Due to the varied mechanisms of diminished MMPs activity, this could be carried out in many ways, including direct inhibition of the enzymes, blocking the activation of proenzyme MMPs, enhancing of MMPs inhibitor production, or suppressing MMPs expression. Both synthetic and natural MMPIs are increasingly sought for use in clinical applications. Besides, MMPIs derived from natural products should display fewer side effects ${ }^{16}$. Interestingly, oxidants can convert pro-MMP to active MMP through binding to the thiol group of a cysteine in the prodomain ${ }^{17,18}$. Hence, this pro-MMP activation could be abrogated by the action of antioxidant agents ${ }^{19,20}$ such as herbs, plants, fruits, and other agriculture products. In addition, flavonoid and polyphenolic compounds also disrupt the pathway of oxidative-stress induced MMPs expression. Their inhibition of MMPs at the levels of both expression and activity was suggested as the mechanism by which flavonoids and polyphenols may impact the extracellular matrix degradation and remodelling leading to the anti-invasion and antimetastatic effects ${ }^{21}$.

In this study, the biological activities of dried longan seed extract were analysed for antioxidant activity and anti MMPs activity. This is the first such screening of dried longan seeds on MMP activity, and is a necessary step for further investigation of the effect of dried longan seed extract on MMPs expression and activity in vitro as well.

\section{MATERIALS AND METHODS}

\section{Chemicals}

Standard gallic acid, catechin, ellagic acid, corilagin, ascorbic acid, $\alpha$-tocopherol and ferene were purchased from Sigma-Aldrich Chemicals (St. Louis, MO). Ammonium iron(II) sulphate was obtained from Merck (Darmstadt, FR Germany). Acetone (AR grade) and methanol (HPLC grade) were obtained from LabScan. Sephadex LH-20 was purchased from GE Healthcare.

\section{Plant materials}

Fresh longan fruits (E. longana cv. Biew Kiew) were purchased from local markets in Chiang Mai, Thailand. Removed seeds were collected and dried in a hot air oven at $50^{\circ} \mathrm{C}$ for $48 \mathrm{~h}$ and then ground to a fine powder.

\section{Extraction and fractionation}

Dried longan seed powders were extracted with $80 \%$ acetone in ratio $1: 10(\mathrm{w} / \mathrm{v})$ at room temperature for $24 \mathrm{~h}$. The resulting slurries were filtered through a Whatman No.1 filter paper. The filtrate was evaporated and lyophilized to yield dried longan seed extracts or crude extracts. The crude extracts were dissolved in methanol at $20 \mathrm{mg} / \mathrm{ml}$ and subjected to Sephadex LH-20 column chromatography. The eluate was consecutively collected in $3 \mathrm{ml} /$ tube and the absorbance at $360 \mathrm{~nm}$ measured. Each pooled fraction was collected according to the distinct peak at $360 \mathrm{~nm}$. Each fraction was evaporated and separated for chemical analysis by high performance liquid chromatography (HPLC).

\section{High performance liquid chromatography}

Each fraction at $10 \mathrm{mg} / \mathrm{ml}$ in methanol $(\mathrm{MeOH})$ was separated on a Hypersil ODS-2, $5 \mu \mathrm{M}$ based on type A silica (Thermo Scientific) column $(250 \times 4.6 \mathrm{~mm}$; Thermo-Hypersil Co.). The mobile phases were $80 \%$ $\mathrm{MeOH}$ (solvent $\mathrm{A}$ ) and $0.4 \%$ formic acid (solvent $\mathrm{B}$ ). The flow rate of the mobile phase in the HPLC column was set at $1 \mathrm{ml} / \mathrm{min}$ by using the gradient of solvent $\mathrm{A}$ and solvent $\mathrm{B}$. The separation processes were started from $0-40 \mathrm{~min}$ and detected via a UV detector set at $270 \mathrm{~nm}$. The HPLC column temperature was maintained at $25^{\circ} \mathrm{C}$. The HPLC chromatogram was recorded and the peaks of active compounds identified by comparison with standard gallic acid (GA) and ellagic acid (EA). 


\section{Total phenolic contents}

The Folin-Ciocalteu method was used for the determination of total phenolic compounds with minor modification from a previous method ${ }^{22}$. Briefly, $125 \mu \mathrm{l}$ of standard gallic acid solution $(0-0.32 \mathrm{mg} / \mathrm{ml})$ or $125 \mu \mathrm{l}$ of the fractions at $1 \mathrm{mg} / \mathrm{ml}$ in dimethylsulphoxide (DMSO) was added to $0.5 \mathrm{ml}$ of distilled water and $125 \mu \mathrm{l}$ of Folin-Ciocalteu reagent and then incubated for $10 \mathrm{~min}$. Thereafter, $1.25 \mathrm{ml}$ of $7 \% \mathrm{Na}_{2} \mathrm{CO}_{3}$ and $1 \mathrm{ml}$ of distilled water were added into each sample. Then, all samples were warmed at $45^{\circ} \mathrm{C}$ for $15 \mathrm{~min}$. The absorbance at $765 \mathrm{~nm}$ was measured using a spectrophotometer. The concentration of total phenolic compounds was calculated from gallic acid standard curve and the data was expressed as mg of the gallic acid equivalent (GAE) per $1 \mathrm{~g}$ of dry weight sample.

\section{Total flavonoid contents}

Total flavonoid content was evaluated according to a colorimetric assay with $\mathrm{AlCl}_{3}$ with minor alteration ${ }^{23}$. Briefly, $250 \mu \mathrm{l}$ of standard catechin solution $(0$ $0.32 \mathrm{mg} / \mathrm{ml}$ ) or $250 \mu \mathrm{l}$ of the fractions at $1 \mathrm{mg} / \mathrm{ml}$ in DMSO was mixed with $1.25 \mathrm{ml}$ of distilled water and then $75 \mu \mathrm{l}$ of $5 \% \mathrm{NaNO}_{2}$ was added. After $10 \mathrm{~min}, 150 \mu \mathrm{l}$ of $10 \% \mathrm{AlCl}_{3} \cdot 6 \mathrm{H}_{2} \mathrm{O}$ was added and the mixture stood at room temperature for $10 \mathrm{~min}$. Next, $500 \mu \mathrm{l}$ of $1 \mathrm{M} \mathrm{NaOH}$ and $275 \mu \mathrm{l}$ of distilled water were added. Five minutes later, each sample was mixed and its absorbance at $532 \mathrm{~nm}$ measured using a spectrophotometer. The concentration of total flavonoids was obtained from a catechin standard curve and values were shown as $\mathrm{mg}$ of catechin equivalents (CAE) per $1 \mathrm{~g}$ of dry weight sample.

\section{DPPH-radical scavenging activity}

The scavenging of free radicals was assessed by using the stable 2,2-diphenyl-1-picrylhydrazyl (DPPH) free radical with minor modifications from previously published methods ${ }^{24,25}$. Briefly, $0.1 \mathrm{ml}$ of each fraction at different concentrations $(25-100 \mu \mathrm{g} / \mathrm{ml}$ in $\mathrm{MeOH})$ or positive control $(5 \mu \mathrm{l} / \mathrm{ml}$ in $\mathrm{MeOH} \alpha$-tocopherol and $1 \mathrm{mg} / \mathrm{ml}$ in $\mathrm{MeOH}$ ascorbic acid) was added into $0.1 \mathrm{ml}$ of DPPH solution $(0.2 \mathrm{mM}$ in $\mathrm{MeOH})$ to obtain a final concentrations of each fraction of 12.5$50 \mu \mathrm{g} / \mathrm{ml}$. After $30 \mathrm{~min}$ at $25^{\circ} \mathrm{C}$ in darkness, the absorbance of the mixture was measured at $517 \mathrm{~nm}$. The inhibition of DPPH by the samples was calculated as: $\mathrm{DPPH}$-scavenging activity $=$ (Absorbance of sample - Absorbance of sample blank)/(Absorbance of DPPH control - Absorbance of DPPH control blank).
Sample blank was contained $\mathrm{MeOH}$ instead of DPPH solution. DPPH control included DPPH solution and $\mathrm{MeOH}$, while DPPH control blank was contained only $\mathrm{MeOH}$. Then, the concentration at which $50 \%$ of DPPH scavenging occurs $\left(\mathrm{SC}_{50}\right)$ was read and used for comparative analysis among the fractions.

\section{Metal ion chelating activity}

The chelation of metal ions of the fractions was determined by a modification of a previously published method ${ }^{26}$. Briefly, $4 \mu \mathrm{l}$ of $2 \mathrm{mM}$ ammonium iron(II) sulphate solution was mixed with $80 \mu \mathrm{l}$ of each fraction at different concentrations $(0,400$, and $800 \mu \mathrm{g} / \mathrm{ml}$ in $\mathrm{MeOH})$. The reaction was initiated by the addition of $16 \mu \mathrm{l}$ of $5 \mathrm{mM}$ ferene. The mixture was shaken vigorously and left at room temperature for $10 \mathrm{~min}$. The absorbance of the solution was measured at $593 \mathrm{~nm}$. Methanol was replaced for sample in the control, while the blank of sample or control contained methanol in place of ferene solution. The decrease in ferrous ion oxidation was calculated as: Metal chelating activity $=1-$ (absorbance of sample - absorbance of sample blank)/(absorbance of control - absorbance of control blank).

The results were expressed as the concentration of the extracts that decreased ferrous ions by $50 \%$ $\left(\mathrm{EC}_{50}\right)$.

\section{MMP inhibitor profiling; fluorometric}

The screening of longan seed extract fractions on MMPs activity was carried out using an MMP inhibitor profiling kit (Enzo Life Sciences AK016). Each fraction was prepared at $100 \mu \mathrm{g} / \mathrm{ml}$ in DMSO for interaction with recombinant MMPs (MMP-2, MMP3, MMP-7, MMP-9, MMP-13, and MMP-14) following the manufacturer's instructions. Moreover, in this kit also included broad inhibitor (NNGH) which was used for control inhibitor. The mixture was placed in an incubator $37^{\circ} \mathrm{C}$ for $30-60 \mathrm{~min}$. The MMPs activity was measured using an Omni-MMP fluorogenic substrate (BioMol Research) or broad substrate for MMPs and detected the fluorescence signal at Ex/Em $328 / 420 \mathrm{~nm}$. The MMPs activity was calculated as: MMPs activity $=(\mathrm{ABU}$ of sample $/ \mathrm{ABU}$ of MMP control).

The samples were compared to a control that contained assay buffer instead of the samples $(100 \%$ of MMP activity). Ellagic acid (EA) and gallic acid (GA) at $15 \mu \mathrm{M}$ were used to compare the attenuated capacities on MMPs activity to each fraction. 


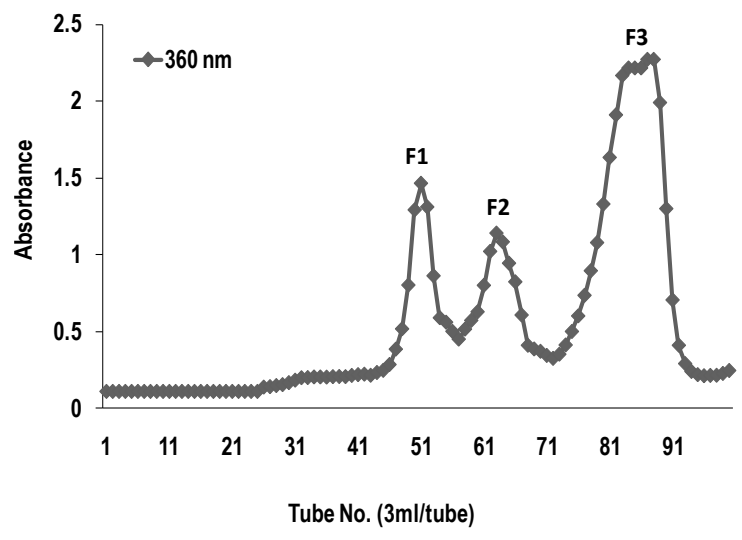

Fig. 1 Isolation of dried longan seed acetone extract by using Sephadex LH-20 column chromatography. Crude acetone extract at $20 \mathrm{mg} / \mathrm{ml}$ in methanol was subjected into Sephadex LH-20 column chromatography which eluted with methanol at flow rate $1 \mathrm{ml} / \mathrm{min}$. The eluates were collected at $3 \mathrm{ml} /$ tube and measured the absorbance at $360 \mathrm{~nm}$. Then, the 3 major fractions were collected by following this graph. $\mathrm{F} 1$, fraction 1; F2, fraction 2; and F3, fraction 3 .

\section{Statistical analysis}

The results are presented as mean $\pm \mathrm{SD}$ of at least three independent experiments. All data were analysed via one-way ANOVA using the SPSS software. Differences were considered significant at $p \leqslant 0.05$.

\section{RESULTS AND DISCUSSION}

\section{Isolation and identification of gallic acid and ellagic acid from dried longan seed fractions}

The acetone extract of dried longan seed extract was further isolated using Sephadex LH-20 column chromatography with methanol, resulting in 3 major fractions (fraction 1, fraction 2, and fraction 3 ) as illustrated in Fig. 1. The yields of each fraction were 3.1, 0.8 , and $4.1 \mathrm{~g} / 200 \mathrm{~g} \mathrm{DW}$, respectively. HPLC analysis was used for determination of the major compounds in each fraction which was compared with the retention time (RT) of gallic acid and ellagic acid standard (RT of gallic acid $=11.3 \mathrm{~min}$, and ellagic acid $=25.6 \mathrm{~min}$ ). Our HPLC chromatogram indicated that gallic acid was found mostly in fraction 1, while ellagic acid was dominant in fraction 3. However, fraction 2 contained small amounts of these two compounds mixed with unidentified components. Table 1 shows the quantification of total gallic acid was significantly higher in fraction $1(p \leqslant 0.05)$ as compared to the others, the amount of ellagic acid was significantly $(p \leqslant 0.05)$ enriched in fraction 3. These compounds were clearly separated in each fraction included GA-
Table 1 The gallic acid and ellagic acid contents of dried longan seed fractions.

\begin{tabular}{lccc}
\hline & F1 & F2 & F3 \\
\hline Gallic acid $(\mu \mathrm{g} / \mathrm{ml})$ & $206 \pm 34^{*}$ & $32 \pm 7$ & $7.7 \pm 3.5$ \\
Ellagic acid $(\mu \mathrm{g} / \mathrm{ml})$ & $22 \pm 6$ & $30 \pm 12$ & $217 \pm 76^{*}$ \\
\hline
\end{tabular}

* Significantly different value at $p \leqslant 0.05$ as compared to the others.<smiles>O=C(O)c1cc(O)c(O)c(O)c1</smiles><smiles>O=c1oc2c(O)c(O)cc3c(=O)oc4c(O)c(O)cc1c4c23</smiles>

Fig. 2 The structures of (a) gallic acid and (b) ellagic acid.

enriched fraction 1 and EA-plentiful fraction 3. Moreover, both of them have been reported to be good scavengers of free radicals and possess the potential of anti-cancer properties ${ }^{27-30}$. Thus their antioxidant capacity might be inherent to be the potent antioxidant of dried longan seed extract. Their structures are shown in Fig. 2.

\section{Antioxidant activities of dried longan seed fractions}

The antioxidant assays included total phenolic acid contents, total flavonoid contents, DPPH scavenging activity and metal ion chelating activity were used to determine the antioxidant capacity of each fraction. Fraction 1 had a significantly higher $(p \leqslant 0.05)$ quantity of total phenolic and flavonoid contents (Table 2). In addition, the $\mathrm{SC}_{50}$ of $\mathrm{DPPH}$ scavenging and $\mathrm{EC}_{50}$ of metal chelating activity were correlated with the amount of phenolic compounds and flavonoids. The assays showed that GA-rich fraction 1 was the most effective in regard to antioxidant activity. Interestingly, other phenolic compounds in longan seeds have been also reported by HPLC-ESIMS analysis such as ethyl gallate, methyl brevifolin carboxylate, brevifolin, 4-O- $\alpha$-L-rhamnopyranosylellagic acid and 1-O-galloyl- $\beta$-D-glucopyranoside ${ }^{31}$. Later, Zhang et $\mathrm{al}^{16}$ reported that these compounds might be the important contributors to the high antioxidant activity in longan seeds other than the predominant gallic acid and ellagic acid. Their results also indicated the decrease in antioxidant by DPPH scavenging as- 
Table 2 The antioxidant activities of dried longan seed fractions.

\begin{tabular}{lccc}
\hline & F1 & F2 & F3 \\
\hline $\begin{array}{l}\text { Total phenolic acid } \\
(\mathrm{mg} \text { GAE/g DW) }\end{array}$ & $203 \pm 13^{*}$ & $123 \pm 13$ & $121 \pm 4$ \\
$\begin{array}{l}\text { Total flavonoid } \\
(\mathrm{mg} \text { CAE/g DW) }\end{array}$ & $89 \pm 6^{\#}$ & $80 \pm 4$ & $53 \pm 6$ \\
$\begin{array}{l}\text { DPPH scavenging activity } \\
\left(\mathrm{SC}_{50} ; \mu \mathrm{g} / \mathrm{ml}\right)^{\mathrm{a}}\end{array}$ & $14 \pm 2^{\#}$ & $20 \pm 3$ & $41 \pm 7$ \\
$\begin{array}{l}\text { Metal chelating activity } \\
\left(\mathrm{EC}_{50} ; \mu \mathrm{g} / \mathrm{ml}\right)^{\mathrm{b}}\end{array}$ & $563 \pm 64$ & $603 \pm 54$ & $615 \pm 16$ \\
\hline
\end{tabular}

* Significantly different at $p \leqslant 0.05$ as compared to F2 and F3.

\# Significantly different at $p \leqslant 0.05$ as compared to F3. Note: Percent of DPPH scavenging ability of $5 \mu \mathrm{g} / \mathrm{ml}$ $\alpha$-tocopherol and $1 \mathrm{mg} / \mathrm{ml}$ ascorbic acid (positive controls) was $96.7 \pm 0.5$ and $95.9 \pm 1.9$, respectively.

${ }^{a} \mathrm{SC}_{50}=$ The concentration of fraction that scavenges $50 \%$ of DPPH radicals.

${ }^{\mathrm{b}} \mathrm{EC}_{50}=$ The concentration of fraction that chelates $50 \%$ of ferrous ion.

All data are expressed as mean $\pm \mathrm{SD}$ from three different experiments conducted in duplicate.

say in the order: gallic acid, ethyl gallate, methyl brevifolin carboxylate, corilagin, ellagic acid, brevifolin, 1-O-galloyl- $\beta$-D-glucopyranoside, and 4-O- $\alpha$ L-rhamnopyranosylellagic acid. Fraction 1 belonged to GA-rich which might be the main compound contributing to high antioxidant capacity.

\section{Anti-MMPs activity of dried longan seed fractions}

Several natural compounds have been identified as MMPIs, such as the extract of baicalin, cinnamon, euonymus, and magnolia ${ }^{32-34}$. Six recombinant MMPs were used for determination of inhibitory effects of each fraction, including MMP-2 and MMP-9 for gelatinases, MMP-3 for stromelysin, MMP-7 for matrilysin, MMP-13 for collagenase, and MMP-14 for membrane type MMP. The inhibitory profiling of dried longan seed fractions is shown in Fig. 3. The present results indicate that each fraction significantly inhibits a broad range of MMP family. Among of fractions, EA-enriched fraction 3 was possessed as the strongest MMPs inhibitor and seemed to have more inhibitory potency than EA and GA control. In the other words, the synergistic effect of the mixture compounds in dried longan seed fractions might be manipulated to enhance the anti-MMP activity effect, particularly in EA-dominant fraction 3.

Shortcomings of the first generation of MMPIs development include unsatisfying effects on some

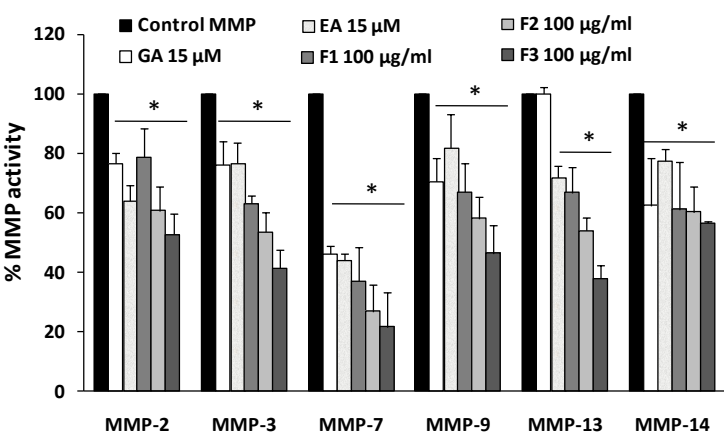

Fig. 3 The effect of the fractions from dried longan seed extract on MMPs activity by using fluorometric assay. Six recombinants MMPs were represented for the major MMP groups consist of MMP-3, stromelysin; MMP-7, matrilysin; MMP-2 and -9, gelatinases; MMP-13, collagenase; and MMP-14, membrane type MMP. Each fraction at $100 \mu \mathrm{g} / \mathrm{ml}$ or ellagic acid and gallic acid at $15 \mu \mathrm{M}$ was reacted with each MMP in 96 wells plate to form sample (inhibitor)/MMP complexes at $37^{\circ} \mathrm{C}$ for 30-60 min. Thereafter, Omni-MMP fluorescence substrate was added into the reaction and then measured the fluorescence light at Ex/Em 328/420 nm. (* significantly different at $p \leqslant 0.05$ as compared with control MMP).

physiological functions and on some metalloproteinases such as ADAMs ${ }^{35,36}$. A new generation of MMPIs should be based on either selective MMP inhibition or on different inhibitory mechanisms to increase the specificity ${ }^{37-40}$. In this case, a limitation of MMPs kit is that it contains all recombinant MMPs where only the catalytic domain and not the full length MMP structure is present. Therefore, their non-selective inhibition effect could be explained that $\mathrm{Zn}^{2+}$ containing in catalytic domain of all MMPs might be the target for the action of each, in other word each fraction might be playing a role in $\mathrm{Zn}^{2+}$ chelation activity. Since $\mathrm{Zn}^{2+}$ is essential for MMPs proteolytic activity, the possible effect of each fraction on $\mathrm{Zn}^{2+}$ chelation activity leads to undistinguishable effect of the different MMPs. In addition, Ende et al ${ }^{41}$ reported that a numerous flavonoid compounds inhibit recombinant MMP-2 and MMP-9 ${ }^{41}$. Although the definite inhibitory mechanism is unclear, it is believed that the present of hydroxyl groups or carbonyl groups on their phenolic rings can chelate active $\mathrm{Zn}^{2+}$ ions and inhibit MMPs activity ${ }^{42,43}$. In fact, not only $\mathrm{Zn}^{2+}$ is important for proteolytic activity of MMPs, but also calcium ion $\left(\mathrm{Ca}^{2+}\right)$ are also needed for activity and to maintain the conformation of MMPs ${ }^{44}$. Hence, both of essential metals might be synergistically chelated 
by the flavonoid compounds in fraction 3 .

Although this study did not determine the action of dried longan seed fractions on MMP-activity unequivocally, there is evidence indicating a correlation between antioxidant and anti-MMP activity via a decrease in oxidative stress and free radicals by antioxidant agents which diminish pro-MMPs activation ${ }^{19,20}$. Oxidants can convert pro-MMP to active MMP by binding to the thiol group of a cysteine in the prodomain ${ }^{17,18}$ and interrupt Cys- $\mathrm{Zn}^{2+}$ interaction. This study is first to report the anti-MMPs activity of dried longan seed extract, and the development of MMPI derived from natural product may be possible in a near future. Even though dried longan seed fractions could not be used as MMPI or drugs in clinical trials yet, activities of dried longan seed extract other than the well known antioxidant capacity are interesting and should be further investigated in the future.

Acknowledgements: This study was supported by a grant of the Royal Golden Jubilee PhD programme.

\section{REFERENCES}

1. Rangkadilok N, Worasuttayangkurn L, Bennett RN, Satayavivad J (2005) Identification and quantification of polyphenolic compounds in longan (Euphoria longana Lam.) fruit. J Agr Food Chem 53, 1387-92.

2. Rangkadilok N, Sitthimonchai S, Worasuttayangkurn L, Mahidol C, Ruchirawat M, Satayavivad J (2007) Evaluation of free radical scavenging and antityrosinase activities of standardized longan fruit extract. Food Chem Toxicol 45, 328-36.

3. Raina K, Rajamanickam S, Deep G, Singh M, Agarwal R, Agarwal C (2008) Chemopreventive effects of oral gallic acid feeding on tumor growth and progression in TRAMP mice. Mol Canc Therapeut 7, 1258-67.

4. Yoshioka K, Kataoka T, Hayashi T, Hasegawa M, Ishi Y, Hibasami H (2000) Induction of apoptosis by gallic acid in human stomach cancer KATO III and colon adenocarcinoma COLO 205 cell lines. Oncol Rep 7, 1221-3.

5. Inoue M, Suzuki R, Koide T, Sakaguchi N, Ogihara Y, Yabu Y (1994) Antioxidant, gallic acid, induces apoptosis in HL-60RG cells. Biochem Biophys Res Comm 204, 898-904.

6. Ohno Y, Fukuda K, Takemura G, Toyota M, Watanabe M, Yasuda N, Xinbin Q, Maruyama R, et al (1999) Induction of apoptosis by gallic acid in lung cancer cells. Anti Canc Drugs 10, 845-51.

7. Dorai T, Aggarwal BB (2004) Role of chemopreventive agents in cancer therapy. Canc Lett 215, 129-40.

8. Seeram NP, Adams LS, Henning SM, Niu Y, Zhang Y, Nair MG, Heber D (2005) In vitro antiproliferative, apoptotic and antioxidant activities of punicalagin, el- lagic acid and a total pomegranate tannin extract are enhanced in combination with other polyphenols as found in pomegranate juice. J Nutr Biochem 16, 360-7.

9. Stoner GD, Mukhtar H (1995) Polyphenols as cancer chemopreventive agents. J Cell Biochem Suppl 22, 169-80.

10. Festa F, Aglitti T, Duranti G, Ricordy R, Perticone P, Cozzi R (2001) Strong antioxidant activity of ellagic acid in mammalian cells in vitro revealed by the comet assay. Anticancer Res 21, 3903-8.

11. Banzouzi JT, Prado R, Menan H, Valentin A, Roumes$\tan$ C, Mallie M, Pelissier Y, Blache Y (2002) In vitro antiplasmodial activity of extracts of Alchornea cordifolia and identification of an active constituent: ellagic acid. J Ethnopharmacol 81, 399-401.

12. Yu YM, Chang WC, Wu CH, Chiang SY (2005) Reduction of oxidative stress and apoptosis in hyperlipidemic rabbits by ellagic acid. $J$ Nutr Biochem 16, 675-81.

13. Nagase H, Woessner JF, Jr (1999) Matrix metalloproteinases. J Biol Chem 274, 21491-4.

14. Bode W, Maskos K (2003) Structural basis of the matrix metalloproteinases and their physiological inhibitors, the tissue inhibitors of metalloproteinases. Biol Chem 384, 863-72.

15. Maskos K (2005) Crystal structures of MMPs in complex with physiological and pharmacological inhibitors. Biochimie 87, 249-63.

16. Zhang C, Kim SK (2009) Matrix metalloproteinase inhibitors (MMPIs) from marine natural products: the current situation and future prospects. Mar Drugs 7, 71-84.

17. Grant GA, Goldberg GI, Wilhelm SM, He C, Eisen AZ (1992) Activation of extracellular matrix metalloproteases by proteases and organomercurials. Matrix Suppl 1, 217-23.

18. Somerville RP, Oblander SA, Apte SS (2003) Matrix metalloproteinases: old dogs with new tricks. Genome Biol 4, 216.

19. Wenk J, Brenneisen P, Wlaschek M, Poswig A, Brivida K, Oberley TD, Scharffetter-Kochanek K (1999) Stable overexpression of manganese superoxide dismutase in mitochondria identifies hydrogen peroxide as a major oxidant in the AP-1-mediated induction of matrix-degrading metalloprotease-1. J Biol Chem 274, 25869-76.

20. Buhimschi IA, Kramer WB, Buhimschi CS, Thompson LP, Weiner CP (2000) Reduction-oxidation (redox) state regulation of matrix metalloproteinase activity in human fetal membranes. Am J Obstet Gynecol 182, 458-64.

21. Sang QX, Jin Y, Newcomer RG, Monroe SC, Fang X, Hurst DR, Lee S, Cao Q, et al (2006) Matrix metalloproteinase inhibitors as prospective agents for the prevention and treatment of cardiovascular and neoplastic diseases. Curr Top Med Chem 6, 289-316.

22. Oskoueian E, Abdullah N, Hendra R, Karimi E (2011) Bioactive compounds, antioxidant, xanthine oxidase 
inhibitory, tyrosinase inhibitory and anti-inflammatory activities of selected agro-industrial by-products. Int $J$ Mol Sci 12, 8610-25.

23. Hendra R, Ahmad S, Oskoueian E, Sukari A, Shukor MY (2011) Antioxidant, anti-inflammatory and cytotoxicity of Phaleria macrocarpa (Boerl.) Scheff Fruit. BMC Compl Alternat Med 11, 110.

24. Duan X, Wu G, Jiang Y (2007) Evaluation of the antioxidant properties of litchi fruit phenolics in relation to pericarp browning prevention. Molecules 12, 759-71.

25. Sarni-Manchado P, Le Roux E, Le Guerneve C, Lozano Y, Cheynier V (2000) Phenolic composition of litchi fruit pericarp. J Agr Food Chem 48, 5995-6002.

26. Dinis TC, Maderia VM, Almeida LM (1994) Action of phenolic derivatives (acetaminophen, salicylate, and 5-aminosalicylate) as inhibitors of membrane lipid peroxidation and as peroxyl radical scavengers. Arch Biochem Biophys 315, 161-9.

27. Kawada M, Ohno Y, Ri Y, Ikoma T, Yuugetu H, Asai T, Watanabe M, Yasuda N, et al (2001) Anti-tumor effect of gallic acid on LL-2 lung cancer cells transplanted in mice. Anti Canc Drugs 12, 847-52.

28. Lee KW, Hur HJ, Lee HJ, Lee CY (2005) Antiproliferative effects of dietary phenolic substances and hydrogen peroxide. J Agr Food Chem 53, 1990-5.

29. Losso JN, Bansode RR, Trappey A, 2nd Bawadi HA, Truax R (2004) In vitro anti-proliferative activities of ellagic acid. $J$ Nutr Biochem 15, 672-8.

30. Saleem A, Husheem M, Harkonen P, Pihlaja K (2002) Inhibition of cancer cell growth by crude extract and the phenolics of Terminalia chebula Retz. fruit. J Ethnopharmacol 81, 327-36.

31. Soong YY, Barlow PJ (2005) Isolation and structure elucidation of phenolic compounds from longan ( $\mathrm{Di}$ mocarpus longan Lour.) seed by high-performance liquid chromatography-electrospray ionization mass spectrometry. J Chrom A 1085, 270-7.

32. Seo UK, Lee YJ, Kim JK, Cha BY, Kim DW, Nam KS, Kim CH (2005) Large-scale and effective screening of Korean medicinal plants for inhibitory activity on matrix metalloproteinase-9. J Ethnopharmacol 97, 101-6.

33. Ha KT, Lee TK, Kwak KH, Kim JK, Kim DI, Choi DY, Kim CH (2004) Inhibitory effect of Cho-DeungSan on human aortic smooth muscle cell migration induced by TNF-alpha through inhibition of matrix metalloproteinase-2 and -9 activity. Vasc Pharmacol 41, 83-90.

34. Ha KT, Kim JK, Kang SK, Kim DW, Lee YC, Kim HM, Kim CH (2004) Inhibitory effect of Sihoga-YonggolMoryo-Tang on matrix metalloproteinase- 2 and -9 activities and invasiveness potential of hepatocellular carcinoma. Pharmacol Res 50, 279-85.

35. Overall CM, Lopez-Otin C (2002) Strategies for MMP inhibition in cancer: innovations for the post-trial era. Nat Rev Canc 2, 657-72.

36. Overall CM, Kleifeld O (2006) Tumour microenviron- ment - opinion: validating matrix metalloproteinases as drug targets and anti-targets for cancer therapy. Nat Rev Canc 6, 227-39.

37. Overall CM, Blobel CP (2007) In search of partners: linking extracellular proteases to substrates. Nat Rev Mol Cell Biol 8, 245-57.

38. Wasserman ZR (2005) Making a new turn in matrix metalloprotease inhibition. Chem Biol 12, 143-4.

39. Engel CK, Pirard B, Schimanski S, Kirsch R, Habermann J, Klingler O, Schlotte V, Weithmann KU, et al (2005) Structural basis for the highly selective inhibition of MMP-13. Chem Biol 12, 181-9.

40. Dublanchet AC, Ducrot P, Andrianjara C, O'Gara M, Morales R, Compere D, Denis A, Blais S, et al (2005) Structure-based design and synthesis of novel non-zinc chelating MMP-12 inhibitors. Bioorg Med Chem Lett 15, 3787-90.

41. Ende C, Gebhardt R (2004) Inhibition of matrix metalloproteinase-2 and -9 activities by selected flavonoids. Planta Med 70, 1006-8.

42. Mannello F (2006) Natural bio-drugs as matrix metalloproteinase inhibitors: new perspectives on the horizon? Recent Patents Anti Canc Drug Discov 1, 91-103.

43. Whittaker M, Floyd CD, Brown P, Gearing AJ (1999) Design and therapeutic application of matrix metalloproteinase inhibitors. Chem Rev 99, 2735-76.

44. Lee S, Park HI, Sang QX (2007) Calcium regulates tertiary structure and enzymatic activity of human endometase/matrilysin- 2 and its role in promoting human breast cancer cell invasion. Biochem J 403, 31-42. 